\title{
Calculation of Sound Insulation for Hybrid CLT Fabricated with Lumber and LVL and comparison with experimental data.
}

\author{
Zehui $\mathrm{Ju}^{1}$, Qian $\mathrm{He}^{1}$, Haiyang Zhang ${ }^{1}$, Tianyi Zhan ${ }^{1}$, Lu Hong ${ }^{1}$, Yangfan $\operatorname{Lin}^{2}$, Xiaoning Lu ${ }^{1, *}$ \\ ${ }^{1}$ College of Materials Science and Engineering, Nanjing Forestry University, Nanjing 210037, P.R. China \\ ${ }^{2}$ College of Science, Nanjing Forestry University, Nanjing 210037, P.R. China
}

\begin{abstract}
The insulated predictions were carried out for LVL, CLT and HCLT in order to evaluate their sound properties, in which the theoretical value of sound insulation was predicted by regarding the substances in wood cell wall as equivalence to specific medium based on Biot model, and the wood anatomical characteristics, such as the length and diameter of tracheid, diameter of pit, and porosity, were taken into account for determining the equivalent density and bulk modulus of elasticity of wood cell wall. By comparing the tested and predicted values of sound insulation, the conclusion were drawn as follows: the predicted values of sound insulation were significantly correlated with the tested values for LVL, CLT and HCLT. As for Masson pine and Southern pine, the adjacent of earlywood and latewood was considered as sandwich structure for the calculation of sound insulation. Meanwhile, the bonding interface was creatively introduced to improve the accuracy of sound insulation prediction. The transfer function involved in sound insulation prediction provide an effective method to characterize the sound insulation volume of wood composite in construction and decoration areas.
\end{abstract}

\section{Introduction}

Wood is one of the most environmental renewable building material, which has been widely utilized in construction, transportation and decoration industry. Since its development in the mid-1990s, cross-laminated timber (CLT) has become a well-established engineered wood product with consistently increasing production volumes[1]. CLT can be characterized as a panel-shaped structural product that consists of at least three layers of strength graded timber that are orthogonally oriented to each other[2]. The cross lamination leads to dimensional stability as well as homogenized material properties[3]. However, generic CLT is known to be prone to the socalled planar (rolling) shear failure and excessive deflection when subjected to out-of-plane loading with short spans or openings. Planar shear strength and stiffness in CLT should be considered in the design of CLT floor systems[4]. Planar stress is defined as shear stress leading to shear strains in a plane perpendicular to the grain direction of wood[5]. Recently, the concept of hybrid CLT (HCLT) has been demonstrated by replacing one or more layers of lumber with SCL, e.g. laminated strand lumber (LSL), to improve the planar shear and bending properties of CLT. Gong et al.[6] evaluated the planar shear properties of hardwoods, including aspen (Populus tremuloides), white birch (Betula papyrifera) and yellow birch (Betula alleghaniensis). Their experimental results showed that hardwoods exhibited larger planar shear strengths than softwoods such as black spruce (Picea mariana). They suggested that use of hardwoods as cross layer(s) in fabrication of CLT could significantly improve its planar shear performance. Wang et al.[7] evaluated the bending properties (in major strength direction) of hybrid CLT (HCLT) fabricated using lumber and/or LVL. It was found that SPF had higher planar shear strength and modulus than LVL. The failure mode of HCLT with LVL as cross layer in planar shear test was shear failure along the glue line direction, however, the typical failure modes of HCLT with SPF as cross layer in planar shear test included rolling shear failure along the growth ring direction, shear failure along the wood ray direction and shear failure along glue line direction.

It is necessary to study the sound insulation quantity on the basis of studying the mechanical properties of CLT. Sound insulation has been investigated for a long time as one of the most crucial and interesting issue among the building environments[8]. The sound insulation of wood building material has been studied mainly by experiments, such as the measurement on the sound insulation properties of different constructional element in the laboratory. The Canadian Institute of FPInnovations and the American Timber Association have conducted extensive trials on the sound insulation properties of CLT walls and floors in different structures $[9,10]$. In recent years, the prediction of sound insulation has become reality with the development of computer technology, such as the finite element method (FEM), sound research using the boundary element method (BEM) and statistical energy analysis method (SEA). The coefficients of the linear equations of the

Corresponding author: luxiaoning-nfu@,126.com 
model parameters was assigned and the factors of sound insulation were discussed. The study of lateral transaudient and the prediction of the whole building sound insulation has been investigated by R. J. M. Craik applied the SEA method[11]. From the aspect of theory of wood sound insulation, the microscopic characteristic of wood such as the porous structure played a significance role in the sound insulation theory while it had been rarely investigated by researchers as a porous material especially involved in the model of the wood sound insulation.

On account of the micro-characteristic of wood material, length and diameter of tracheid, diameter of pit, porosity are as influence factors considered in the establishment of model of wood material sound insulation using wave propagation theory, which is revised by the special flow resistance in wood material and applied for the prediction of softwood sound insulation. At the same time, the influence of the adhesive was introduced on the sound insulation of the material. The sound insulation volume of CLT and HCLT were measured by experimental method under wide frequency with the comparison of the predicted value of the novel model.

\section{SOUND INSULATION PREDICTION AND MOE PREDICTION}

\subsection{SOUND INSULATION PREDICTION}

The material is assumed to be transversely infinite and the sound wave is perpendicular to the surface of the plate in air medium. The wood frame is assumed as a rigid body. The sound propagation in wood can be considered as a fluid motion, which can be equivalent to the calculation of fluid model. The sound propagation theory of Biot for elastic porous medium is applied in the model. Besides, the effect of air and hole wall on viscosity and the effect of heat exchange are also considered, which are described in the Zwikker model, Kosten model and Stinson model respectively[12-18]. The $\rho$ represents wood density and the $\mathrm{K}$ represents equivalent volume modulus[19].

$$
\begin{gathered}
\rho=\rho_{0} \alpha_{\infty}\left(1+\frac{\sigma \phi}{j \alpha_{\infty} \rho_{0} \omega} G_{J}(\varpi)\right) \\
K=\frac{\gamma P_{0}}{\gamma-(\gamma-1)\left[1+\frac{\sigma \phi}{j B^{2} \omega \rho_{0} \alpha_{\infty}} G_{J}^{\prime}\left(B^{2} \omega\right)\right]^{-1}} \\
G_{J}^{\prime}\left(B^{2} \omega\right)=\left(1+\frac{4 j \alpha_{\infty}^{2} \eta \rho_{0} \omega B^{2}}{\sigma^{2} \Lambda^{\prime 2} \phi^{2}}\right)^{\frac{1}{2}} \\
G_{J}(\varpi)=\left(1+\frac{4 j \alpha_{\infty}^{2} \eta \rho_{0} \omega}{\sigma^{2} \Lambda^{2} \phi^{2}}\right)^{\frac{1}{2}} \\
\Lambda=\frac{1}{\mathrm{c}}\left(\frac{8 \eta \alpha_{\infty}}{\sigma \phi}\right)^{\frac{1}{2}} \\
\sigma=\frac{n^{*} n_{p t} *(1-b) * \pi * r^{4} * L^{*}(1-\alpha)}{D_{e}^{2} * 8 * \eta^{*} L_{p m}} * 1.013 * 10^{6}
\end{gathered}
$$

Where the $\rho_{0}$ is the density of air and $\mathrm{P}_{0}$ is the air pressure. The $\gamma$ is a constant and $\mathrm{B}$ is the Prandtl constant. The $\sigma, \phi$ and $\omega$ represents the flow resistance of porous material, the porosity and the angular velocity respectively. The $\alpha_{\infty}$ is tortuosity. The $\eta$ is the shear viscosity of air and the $r$ is radius of the hole. For circular holes, $\mathrm{c}=1 . \mathrm{A}=\mathrm{D}^{2}{ }_{\mathrm{e}}$. De is the tracheid diameter $(\mathrm{cm}), \mathrm{A}$ is the cross-sectional area of tracheids $\left(\mathrm{cm}^{2}\right), \mathrm{npt}$ is the number of pits, $n$ is the average number of micro pit membrane in each pit, $b$ is the occlusion rate of pits, $r$ is the average radius of micro pit membrane $(\mathrm{cm})$ and $\mathrm{L}$ is the average length of tracheid.

In this study, the standard state (at $18^{\circ} \mathrm{C} 103.3 \mathrm{kPa}$, air parameter $\left.\eta=1.84 \times 10^{-5} \mathrm{kgm}^{-1} \mathrm{~s}^{-1}, \gamma=1.4, \mathrm{~B}^{2}=0.71\right)$ was used in the prediction. The $\mathrm{c}$ is sound wave velocity and $\mathrm{k}_{0}$ is the wave number. The and is the corresponding amount in the condition of air respectively. The $d$ represents the thickness of wood and $\mathrm{k}$ is the number of wood [20,21].

The layout model of any laminated composite plate is shown in Fig.1.

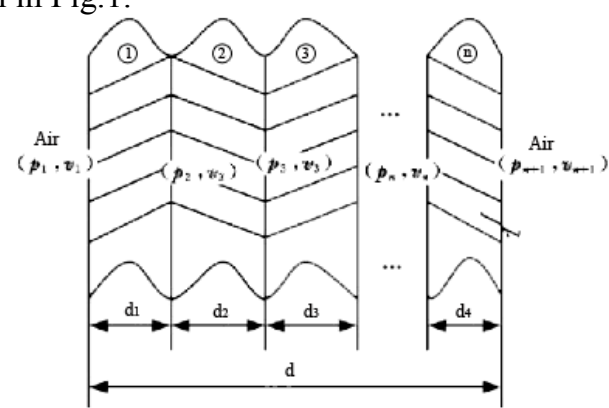

Fig. 1. Layout model of multilayer composite plate

The layer $\mathrm{i}$ material is considered as the object of study.

The transfer matrix i of layer Ti is as follows:

$$
T_{i}=\left[\begin{array}{cc}
\cos \left(k_{i} d_{i}\right) & j \sin \left(k_{i} d_{i}\right) Z_{c} \\
j \sin \left(k_{i} d_{i}\right) / Z_{c} & \cos \left(k_{i} d_{i}\right)
\end{array}\right]
$$

Where the $\mathrm{k}_{0}$ and $\rho_{0}$ are the wave number and density of air medium. The total transfer matrix and the total transfer matrix of the sandwich composite plate are obtained:

$$
T=\prod_{i=1}^{n} T_{i}=\left[\begin{array}{ll}
T_{1,1} & T_{1,2} \\
T_{2,1} & T_{2,2}
\end{array}\right]
$$

The transmission coefficients of multilayer materials can be obtained as follows:

$$
\begin{gathered}
t_{p}=\frac{2}{T_{1,2}+T_{2,2}+T_{1,2} \frac{k_{0}}{\omega \rho_{0}}+T_{2,1} \frac{\omega \rho_{0}}{k_{0}}} \\
T L=20 \lg \left|\frac{1}{t_{p}}\right|
\end{gathered}
$$

\subsection{MOE CALCULATION}

The coincidence effect was occurred at the simulation of material sound insulation. The coincidence effect is related to the critical frequency of the material. $f_{c}=\frac{c_{0}^{2}}{2 \pi} \sqrt{\frac{\rho H}{D}}$ D is the stiffness of material. Therefore, we 
need to predict the MOE of the material. The MOE is tangential elastic module.

Firstly, the microstructure, chemistry, and mechanics of the interphase between wood materials (Southern pine) and adhesives (phenol formaldehyde and urea formaldehyde) at the nanometer level to characterize to indicate the forming mechanism of the interphase. Results indicated that the average penetration depths of the resin from the glueline was about $1.3 \mu \mathrm{m}$, i.e., PF resin penetrated into the $S_{2}$ layer of wood cell wall[22]. So, the glue layer can be separated into one layer in MOE calculation.

It is necessary to predict the mechanical property of Masson pine veneer before the prediction of composite MOE. The models for predicting elastic modulus along the grain of Masson pine veneer were built, in which compression ratio, glue content, density, and thickness of veneer were considered[23-25].

$$
\begin{gathered}
\mathrm{E}_{\mathrm{Li}}=\frac{1}{\left(1-\mathrm{T}_{\mathrm{Vi}} / 100\right)}\left(\frac{\mathrm{D}_{0 \mathrm{i}}}{\mathrm{D}_{\mathrm{fi}}} \mathrm{E}_{\mathrm{fi}}+\frac{\mathrm{A}_{\mathrm{gi}}}{1000 \mathrm{t}_{0} D_{g i}} \mathrm{E}_{\mathrm{gi}}\right) \\
E_{T i}=\frac{D_{0}}{D_{f i}\left(1-T_{v i} / 100\right)} E_{T f i}+\left[\frac{A_{g i}-A_{g p i}}{1000 t_{0}\left(1-T_{v i} / 100\right) D_{g i}}+k k_{2}\left(1-T_{v i} / 100\right)\right] E_{\mathrm{mi}} \\
G_{L T i}=\frac{D_{0}}{D_{f i}\left(1-T_{v i} / 100\right)} G_{L T f i}+\left[\frac{A_{g i}-A_{g p i}}{1000 t_{0}\left(1-T_{v i} / 100\right) D_{g i}}+k k_{2}\left(1-T_{v i} / 100\right)\right] G_{\mathrm{mi}}
\end{gathered}
$$

Where the $\mathrm{E}_{\mathrm{Li}}$ is the elastic modulus along the grain of the Masson pine veneer. $\mathrm{E}_{\mathrm{Ti}}$ is the tangential elastic module of the Masson pine veneer. $\mathrm{G}_{\mathrm{LTi}}$ is the in-plane shearing modulus of the Masson pine veneer. $\mathrm{T}_{\mathrm{Vi}}$ is the rate of the veneer thickness change. $D_{0 \mathrm{i}}$ is the initial density of veneers $\left(\mathrm{g} / \mathrm{cm}^{3}\right) . D_{\mathrm{fi}}$ is the density of the wood. $\mathrm{D}_{\mathrm{gi}}$ is the density of the veneer. $\mathrm{E}_{\mathrm{fi}}$ is the elastic modulus along the grain of Masson pine. $\mathrm{E}_{\mathrm{Tfi}}$ is the tangential elastic module of Masson pine. $\mathrm{G}_{\mathrm{LTFi}}$ is the in-plane shearing modulus of Masson pine. $E_{\mathrm{gi}}$ is the elastic modulus along the grain of the adhesive. $\mathrm{E}_{\mathrm{mi}}$ is the tangential elastic module of the adhesive. $G_{m i}$ is the inplane shearing modulus of the adhesive. $\mathrm{A}_{\mathrm{gi}}$ is solid content $\left(\mathrm{g} / \mathrm{m}^{2}\right) . \mathrm{t}_{0 \mathrm{i}}$ is the initial thickness of veneer $(\mathrm{mm})$. $\mathrm{k}$ is the compression ratios of the veneer. $\mathrm{k}_{2}$ is the wide distance ratio. In-plane Poison's ratio is 0.35 . Therefore, Therefore, the composite MOE can be predicted by the traditional laminate MOE model[26] at Table 1.

Table. 1. MOE simulation.

\begin{tabular}{|c|c|c|c|c|c|c|}
\hline Material & LVL1 & LVL2 & A & B & C & D \\
\hline $\mathrm{MOE} / \mathrm{GPa}$ & 11.43 & 9.84 & 9.81 & 9.92 & 9.80 & 10.49 \\
\hline
\end{tabular}

\section{Material and experiment}

\subsection{Material}

Veneers of Masson pine (Pinus massoniana Lamp.) with the dimension of $400 \mathrm{~mm} \times 400 \mathrm{~mm} \times 2.5 \mathrm{~mm}$ (length $\times$ width $\times$ height) were selected in this study without any defects. They were fabricated in a company in Jiangsu province. Veneers were oven dried at $103^{\circ} \mathrm{C}$ for two days and reach to a stable moisture content of $5 \pm 3 \%$. Southem pine (Pinusspp) with the dimension of $400 \mathrm{~mm}$ $\times 400 \mathrm{~mm} \times 2.5 \mathrm{~mm}$ (length $\times$ width $\times$ height $)$ were selected in this study without any defects. They were fabricated in a company in Shanxi province. Phenol formaldehyde adhesive (PF) was prepared with the ratio of $2: 1$ and the solid content is $45 \%\left(359 \mathrm{mPa} \mathrm{s}, 20^{\circ} \mathrm{C}\right)$. The solid content of UF adhesive is $60 \%$. The viscosity of UF adhesive is $300 \mathrm{mPa} \cdot \mathrm{s}$ measured by the rotational viscometer (DV-79+Pro, China). The experimental adhesive is PUR adhesive provided by $\mathrm{Pu}$ Bang company and its model is HB S309. It is a onecomponent liquid polyurethane adhesive, the main component: isocyanate prepolymer, the chemical composition can make wood and air water chemical reaction to form a strong adhesive layer. The maximum aging time is $30 \mathrm{~min}$, the curing time is $120 \mathrm{~min}$, and the adhesive size is $120-160 \mathrm{~g} / \mathrm{m}^{2}$.

\subsection{LVL, CLT AND HCLT PREPARATION}

The adhesive were applied to the single bonding surface approximately $150 \mathrm{~g} / \mathrm{m}^{2}$ and nine veneers were assembled, which were set in the hot pressing machine. When using UF, the temperature was settled at $110^{\circ} \mathrm{C}$. When using PF, the temperature was settled at $1^{\circ} \mathrm{C}$. The pressure on the LVL was $1 \mathrm{MPa}$ and the whole time of fabricating specimens was calculated by $60 \mathrm{~s} / \mathrm{mm}$. The repetition for each condition was ten. The PF adhesive was used in LVL 1. The UF adhesive was used in LVL 2. Table 2 shows the configuration of each group of 3-layer CLT/HCLT specimen. The thickness of LVL panels was sanded to $20 \mathrm{~mm}$ as well in this study and the adhesive used in LVL was PF. After preparing each layer, the surface of each layer was first cleaned to remove dust. CLT or HCLT specimens were bonded by cold pressing at a pressure of $1 \mathrm{MPa}$ and a holding time of $2.5 \mathrm{~h}$. The cold-pressed material was placed in a dry environment to make the adhesive react fully.

Table. 2. The configuration of CLT/HCLT

\begin{tabular}{|c|c|c|}
\hline Group & $\begin{array}{c}\text { Layer material } \\
\text { (Top-center-bottom) }\end{array}$ & $\begin{array}{c}\text { Layer orientation } \\
\text { (Top-center-bottom) }\end{array}$ \\
\hline A & $\begin{array}{c}\text { Southern pine - Southern pine - Southern } \\
\text { pine }\end{array}$ & $0^{\circ}-90^{\circ}-0^{\circ}$ \\
\hline B & $\begin{array}{c}\text { Southern pine - Southern pine - Southern } \\
\text { pine }\end{array}$ & $0^{\circ}-45^{\circ}-0^{\circ}$ \\
\hline C & Southern pine - LVL 1 - Southern pine & $0^{\circ}-90^{\circ}-0^{\circ}$ \\
\hline D & LVL 1 - Southern pine - LVL 1 & $0^{\circ}-90^{\circ}-0^{\circ}$ \\
\hline
\end{tabular}

\subsection{Measurements}

Scanning electron microscope (SEM)

The sample of $5 \mathrm{~mm} \times 5 \mathrm{~mm} \times 5 \mathrm{~mm}$ was cut from disc, of which the three sections were cut flat via a blade. The samples were stored at room temperature until processing for SEM (TM-1000, Japan) observation. The samples were coated with osmiun tetroxide $\left(\mathrm{O}_{\mathrm{S}} \mathrm{O}_{4}\right)$ in a Plasma Coater (HPC-1SW, Vacuum Device Inc) before imaging. Then, the images were obtained at the condition of vacuum. The accelerating voltage was 
$15000 \mathrm{~V}$, the magnification was 300 and the emission Current was $104.8 \mathrm{~mA}$.

Mercury intrusion porosimetry (MIP)

A disc (15 mm dimeter, $10 \mathrm{~mm}$ thickness ) was cut from the middle of each log. For each disc, the Mercury intrusion porosimetry (MIP) sample $(5 \mathrm{~mm} \times 5 \mathrm{~mm} \times 10$ $\mathrm{mm}$, radial $\times$ tangential $\times$ longitudinal) was cut from disc central position. The samples was dried in an oven at $103 \pm 2^{\circ} \mathrm{C}$ for 24 hours to oven dry moisture content. The MIP characterizing process employed an Autopore TM IV 9500 Automated Mercury Porosimeter (Micromeritics Instrument Corp., US), to force mercury into pores of wood samples with high pressure (maximum pressure was $400 \mathrm{GPa}$ ). Measurements of total intrusion volume, total pore surface area, pore size and distribution were all available. The weights of two samples were 0.014 and $0.022 \mathrm{~g}$, respectively. The rate of pressure increase was automatically controlled by the predefined procedure, with lower rates at lower pressure levels during measured intrusion processes. As pressure increased, mercury was intruded into voids of descending size and the rate of pressure decreased. The pore volume could be derived from the quantity of mercury intruded.The pore distribution was determined with the Washburn equation[27].

Test instrument of sound insulation

Beijing prestige R-Cabin test system was used in the sound insulation test and the sound transmission test needs to test the transfer function of four channels as shown in Fig.2. The impedance tubes are SW $422(63 \mathrm{~Hz}$ to $1600 \mathrm{~Hz})$ and SW $477(800 \mathrm{~Hz}$ to $6300 \mathrm{~Hz})$ as shown in Fig.3. and Fig.4. The diameter of acoustic expansion tube (SW, 100-E) is $100 \mathrm{~mm}$. The distance between microphone 3 and the left side of sample is $150 \mathrm{~mm}$. The distance between microphone 3 position and microphone 4 position is $80 \mathrm{~mm}$. When the frequency range of sound insulation measurement is $400 \sim 1600 \mathrm{~Hz}$, the big tube was selected in the system and the microphone positions of $1,2,3$ and 4 are chosen. The distance between the microphone 3 position and the microphone 9 position is $300 \mathrm{~mm}$. When the frequency range of sound insulation measurement is $63 \sim 500 \mathrm{~Hz}$, the microphone positions of $0,2,3$ and 9 are chosen. The diameter of sample is $100 \mathrm{~mm}$ and the thickness of sample is less than $120 \mathrm{~mm}$. The diameter of acoustic expansion tube (SW, 030-E) is $30 \mathrm{~mm}$. The distance between microphone 7 and the left side of sample is $100 \mathrm{~mm}$. The distance between microphone 7 position and microphone 8 position is 22.5 $\mathrm{mm}$. When the frequency range of sound insulation measurement is $1600 \sim 5500 \mathrm{~Hz}$, the microphone positions of 5, 6, 7 and 8 are chosen. The diameter of sample is $30 \mathrm{~mm}$ and the thickness of sample is less than $80 \mathrm{~mm}$.

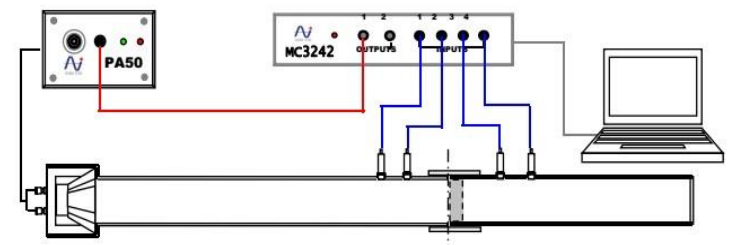

Fig. 2. Test system

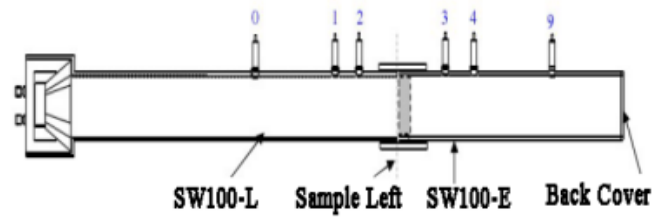

Fig. 3. SW 422 Impedance tube

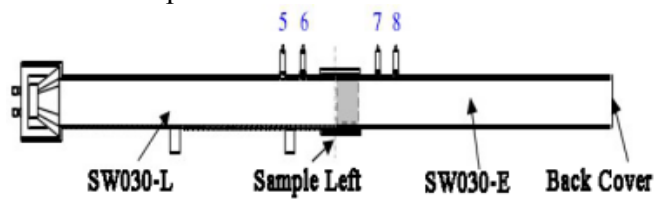

Fig. 4. SW 477 Impedance tube

\section{Results and Discussion}

\subsection{Wood Microscopic Characteristicsby SEM}

It is found that the gas permeability of softwood is closely related to the its flow characteristics and regularities in the tracheid by SEM at Fig. 5 . The arrangement of tracheids in softwood is uniform, which fits the requirement of theoretical prediction. However, many pits are found on the tangential section and radial section of tracheids which aren't considered in the original theory. So the microscopic characteristics of wood should be involved in the theory to revise the model. The characteristic of tracheids and pits are described in the Table 3 .
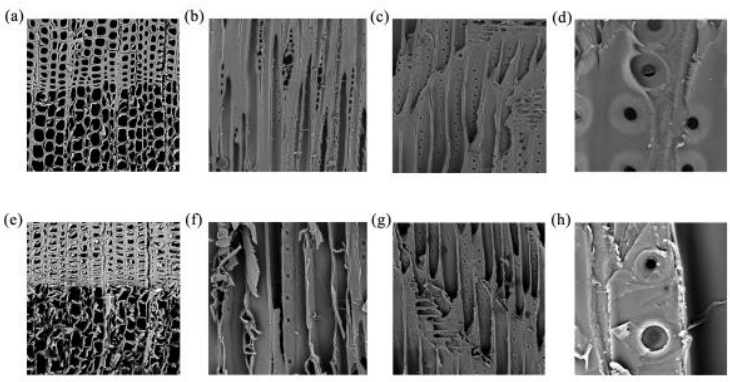

Fig. 5. (a) Transverse section of Southern pine $(\times 300)$, (b) Tangential section of Southern pine $(\times 300)$, (c) Radial section of Southern pine $(\times 300)$, (d) Pit and aspirated pit of Southern pine $(\times 2000)$, (e) Transverse section of Masson Pine $(\times 300)$, (f) Tangential section of Masson Pine $(\times 300)$, (g) Radial section of Masson Pine $(\times 300)$, (h) Pit and aspirated pit of Masson Pine $(\times 2000)$

Table. 3. Weighted average of some structural parameters of tracheids from sampling measurement. 


\begin{tabular}{|c|c|c|c|c|c|c|c|c|}
\hline & & $\begin{array}{l}\mathrm{L}_{\mathrm{pm}} \\
\mu \mathrm{m}\end{array}$ & $\begin{array}{c}\mathbf{D}_{\mathrm{el} 1} \\
\mu \mathrm{m}\end{array}$ & $\begin{array}{l}D_{e 2} \\
\mu m \\
\mu m\end{array}$ & $\begin{array}{l}a \\
\% \\
\end{array}$ & $\begin{array}{l}\mathbf{b} \\
\%\end{array}$ & $n_{p t}$ & $\mathrm{n}$ \\
\hline $\begin{array}{c}\mathrm{LVL} \\
1\end{array}$ & $\begin{array}{c}\text { Masson } \\
\text { Pine }\end{array}$ & 4502.90 & 45.23 & 44.83 & 2.40 & 56.80 & 20 & 155 \\
\hline $\begin{array}{c}\text { LVL } \\
2\end{array}$ & $\begin{array}{l}\text { Masson } \\
\text { Pine }\end{array}$ & 4512.43 & 45.43 & 44.83 & 2.37 & 55.67 & 20 & 154 \\
\hline \multirow{3}{*}{ A } & $\begin{array}{l}\text { Southern } \\
\text { pine }\end{array}$ & 2914.21 & 37.33 & 12.62 & 2.35 & 55.74 & 20 & 163 \\
\hline & $\begin{array}{c}\text { Southerr } \\
\text { pine }\end{array}$ & 3173.77 & 40.13 & 15.17 & 2.30 & 56.21 & 20 & 155 \\
\hline & $\begin{array}{l}\text { Southern } \\
\text { pine }\end{array}$ & 3021.20 & 39.77 & 14.45 & 2.41 & 55.43 & 20 & 159 \\
\hline \multirow{3}{*}{ B } & $\begin{array}{l}\text { Southerer } \\
\text { pine }\end{array}$ & 3162.21 & 39.16 & 13.20 & 2.37 & 55.72 & 20 & 160 \\
\hline & $\begin{array}{l}\text { Southern } \\
\text { pine }\end{array}$ & 2965.72 & 37.55 & 13.17 & 2.37 & 56.24 & 20 & 155 \\
\hline & $\begin{array}{l}\text { Southerr } \\
\text { pine }\end{array}$ & 3114.56 & 38.20 & 15.05 & 2.30 & 57.10 & 20 & 154 \\
\hline \multirow{3}{*}{ C } & $\begin{array}{c}\text { Southern } \\
\text { pine }\end{array}$ & 3016.90 & 38.77 & 13.67 & 2.41 & 55.97 & 20 & 154 \\
\hline & $\begin{array}{c}\text { Masson } \\
\text { Pine }\end{array}$ & 4512.43 & 45.43 & 44.83 & 2.37 & 55.67 & 20 & 154 \\
\hline & $\begin{array}{l}\text { Southern } \\
\text { pine }\end{array}$ & 2957.74 & 39.10 & 14.20 & 2.34 & 56.74 & 20 & 163 \\
\hline \multirow{3}{*}{ D } & $\begin{array}{l}\text { Masson } \\
\text { Pine }\end{array}$ & 4512.43 & 45.43 & 44.83 & 2.37 & 55.67 & 20 & 154 \\
\hline & $\begin{array}{l}\text { Southern } \\
\text { ning }\end{array}$ & 3132.69 & 39.43 & 14.77 & 2.37 & 56.74 & 20 & 155 \\
\hline & $\begin{array}{l}\text { Masson } \\
\text { Pipine }\end{array}$ & 4512.43 & 45.43 & 44.83 & 2.37 & 55.67 & 20 & 154 \\
\hline
\end{tabular}

$\mathrm{L}_{\mathrm{pm}}$ : Tracheid length; $\mathrm{D}_{\mathrm{e} 1}$ : Early wood tracheid diameter; $\mathrm{D}_{\mathrm{e} 2}$ : Latewood tracheid diameter; $\alpha$ :percentage of tracheid overlap; $b$ : percentage of aspirated pit; $\mathrm{n}_{\mathrm{pt}}$ : Umber of pits on the over-lap face of tracheid; $n$ : number of pit membrane openings of a tracheid

\subsection{The Porosity by MIP}

The results from the MIP measurement were shown in Table 4 , and were based to intrusion-extrusion curves, in which the intrusion was used to denote the volume change in the process of pressure increase, and the extrusion indicated the volume change with decreasing pressure. The intrusion-extrusion cycle did not close when the initial pressure was reached, which indicated that some mercury has been permanently entrapped in certain pores. In fact, the path followed by the extrusion curve was not the same as the intrusion path.

Table. 4. The MIP test results

\begin{tabular}{|c|c|c|c|}
\hline \multicolumn{2}{|c|}{ Number } & $\begin{array}{c}\text { Porosity } \\
(\%)\end{array}$ & $\begin{array}{c}\text { Density } \\
\text { (g.cm }{ }^{-3)}\end{array}$ \\
\hline LVL 1 & Masson Pine & 65.54 & 0.45 \\
\hline LVL 2 & Masson Pine & 65.54 & 0.45 \\
\hline \multirow{3}{*}{ A } & Southern pine & 72.4 & 0.39 \\
\hline & Southern pine & 73.1 & 0.39 \\
\hline & Southern pine & 69.9 & 0.39 \\
\hline \multirow{3}{*}{ B } & Southern pine & 71.7 & 0.39 \\
\hline & Southern pine & 69.5 & 0.39 \\
\hline & Southern pine & 70.2 & 0.39 \\
\hline \multirow{3}{*}{$\mathrm{C}$} & Southern pine & 71.3 & 0.39 \\
\hline & Masson Pine & 65.54 & 0.45 \\
\hline & Southern pine & 70.4 & 0.39 \\
\hline \multirow{3}{*}{ D } & Masson Pine & 65.54 & 0.45 \\
\hline & Southern pine & 69.6 & 0.39 \\
\hline & Masson Pine & 65.54 & 0.45 \\
\hline
\end{tabular}

\subsection{Sound Insulation Prediction of LVL1 and LVL2}

The comparison between the simulated and measured sound insulation volume of LVL 1 and LVL 2 were described in the Figure 6. The analog LVL 1 curve was achieved by taking the microscopic characteristics of wood into consideration, the effect of bonding interface and revising the value of high frequency section for LVL 1. The analog LVL 2 curve was achieved by taking the microscopic characteristics of wood into consideration , the effect of bonding interface and revising the value of high frequency section for LVL 2. The correlation between The analog LVL 1 and the test LVL 1 curve was significant at the 0.01 level (bilateral) in the table 5 and 6. The correlation between The analog LVL 2 and the test LVL 2 curve was significant at the 0.01 level (bilateral) in the table 7 and 8 .

It was proved that the theoretical formula can better predict the sound insulation performance of LVL. The sound insulation of LVL 1 and LVL 2 have little difference in the whole frequency section. The amount of sound insulation of LVL 1 pressed by PF is relatively high. At the same time, it can be found that the coincidence effect of the material occurs in advance with LVL 2 at high frequency due to the relatively high MOE of LVL 1.

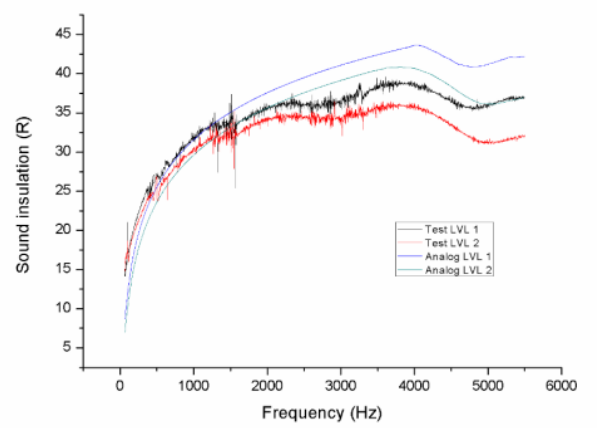

Fig. 6. Simulated sound insulation and measured value of LVL 1 and LVL 2

Table. 5. LVL 1 descriptive statistics

\begin{tabular}{|c|c|c|c|}
\hline & Average value & Standard deviation & Number \\
\hline Test LVL 1 & 34.3662 & 4.34849 & 2719 \\
\hline Analog LVL 1 & 37.4962 & 6.54976 & 2719 \\
\hline
\end{tabular}

Table. 6. LVL 1 correlation analysis

\begin{tabular}{|c|c|c|}
\hline \multirow{3}{*}{ Test LVL 1 } & Pearson Relevance & Test LVL1 \\
\cline { 2 - 3 } & Significance (bilateral) & 1 \\
\cline { 2 - 3 } & Number & 2719 \\
\hline \multirow{3}{*}{ Analog LVL 1 } & Pearson Relevance & $.971^{* *}$ \\
\cline { 2 - 3 } & Significance (bilateral) & .000 \\
\cline { 2 - 3 } & Number & 2719 \\
\hline
\end{tabular}

Significant correlation was found at the 0.01 level (bilateral).

Table. 7. LVL 2 descriptive statistics

\begin{tabular}{|c|c|c|c|}
\hline & Average value & Standard deviation & Number \\
\hline Test LVL 2 & 32.0279 & 3.72229 & 2719 \\
\hline Analog LVL 2 & 34.8864 & 6.11584 & 2719 \\
\hline
\end{tabular}


Table. 8. LVL 2 correlation analysis

\begin{tabular}{|c|c|c|}
\hline \multirow{3}{*}{ Test LVL 2 } & Pearson Relevance & Test LVL2 \\
\cline { 2 - 3 } & Significance (bilateral) & 1 \\
\cline { 2 - 3 } & Number & 2719 \\
\hline \multirow{3}{*}{ Analog LVL 2 } & Pearson Relevance & $.954^{* *}$ \\
\cline { 2 - 3 } & Significance (bilateral) & .000 \\
\cline { 2 - 3 } & Number & 2719 \\
\hline
\end{tabular}

Significant correlation was found at the 0.01 level (bilateral).

\subsection{Sound Insulation Prediction of CLT}

The comparison between the simulated and measured sound insulation volume of A and B were described in the Figure 7. The analog A curve was achieved by taking the microscopic characteristics of wood into consideration, the effect of bonding interface and revising the value of high frequency section for $\mathrm{A}$. The analog B curve was achieved by taking the microscopic characteristics of wood into consideration, the effect of bonding interface and revising the value of high frequency section for $\mathrm{B}$. The correlation between The analog $\mathrm{A}$ and the test A curve was significant at the 0.01 level (bilateral) in the table 9 and 10. The correlation between The analog B and the test B curve was significant at the 0.01 level (bilateral) in the table 11 and 12.

It was proved that the theoretical formula can better predict the sound insulation performance of CLT. The sound insulation of A and B have little difference in the whole frequency section. The amount of sound insulation of $\mathrm{B}$ is relatively high. It can be considered that $\mathrm{A}$ and $\mathrm{B}$ material are consistent with the sound insulation in $0 \sim 5500 \mathrm{~Hz}$ frequency section by ignoring the material and the influence of test error. It can be found that the change of the layer orientation of the CLT does not affect the sound insulation of the material in the $0 \sim 5500 \mathrm{hz}$. It can only change the amount of sound insulation in the critical frequency section by changing the layer orientation of the CLT.

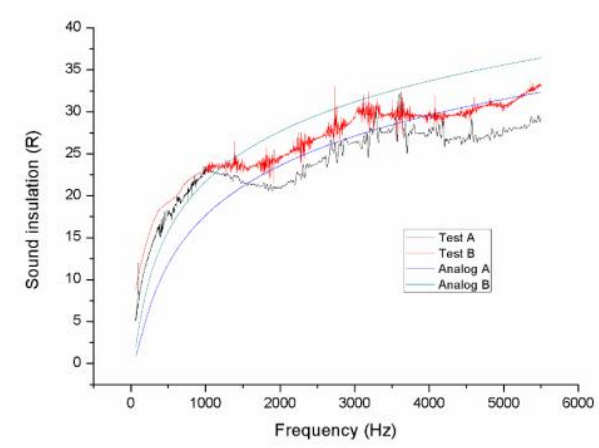

Fig. 7. Simulated sound insulation and measured value of CLT

Table. 9. A descriptive statistics

\begin{tabular}{|c|c|c|c|}
\hline & Average value & Standard deviation & Number \\
\hline Test A & 24.7237 & 4.49144 & 2719 \\
\hline Analog A & 25.4004 & 7.32457 & 2719 \\
\hline
\end{tabular}

Table. 10. A correlation analysis

\begin{tabular}{|c|c|c|}
\hline \multirow{2}{*}{ Test A } & Pearson Relevance & Test A \\
\cline { 2 - 3 } & Significance (bilateral) & 1 \\
\cline { 2 - 3 } & Number & 2719 \\
\hline \multirow{3}{*}{ Analog A } & Pearson Relevance & $.950^{* *}$ \\
\cline { 2 - 3 } & Significance (bilateral) & .000 \\
\cline { 2 - 3 } & Number & 2719 \\
\hline
\end{tabular}

Significant correlation was found at the 0.01 level (bilateral).

Table. 11. B descriptive statistics

\begin{tabular}{|c|c|c|c|}
\hline & Average value & Standard deviation & Number \\
\hline Test B & 27.4976 & 5.15928 & 2719 \\
\hline Analog B & 29.4127 & 7.50308 & 2719 \\
\hline
\end{tabular}

Table. 12. B correlation analysis

\begin{tabular}{|c|c|c|}
\hline \multirow{3}{*}{ Test B } & Pearson Relevance & Test B \\
\cline { 2 - 3 } & Significance (bilateral) & 1 \\
\cline { 2 - 3 } & Number & 2719 \\
\hline \multirow{3}{*}{ Analog B } & Pearson Relevance & $.972^{* *}$ \\
\cline { 2 - 3 } & Significance (bilateral) & .000 \\
\cline { 2 - 3 } & Number & 2719 \\
\hline
\end{tabular}

Significant correlation was found at the 0.01 level (bilateral).

\subsection{Sound Insulation Prediction of HCLT}

The comparison between the simulated and measured sound insulation volume of $\mathrm{A}, \mathrm{C}$ and $\mathrm{D}$ were described in the Figure 8. The analog A curve was achieved by taking the microscopic characteristics of wood into consideration, the effect of bonding interface and revising the value of high frequency section for $\mathrm{A}$. The analog $\mathrm{C}$ curve was achieved by taking the microscopic characteristics of wood into consideration, the effect of bonding interface and revising the value of high frequency section for $\mathrm{C}$. The analog $\mathrm{D}$ curve was achieved by taking the microscopic characteristics of wood into consideration, the effect of bonding interface and revising the value of high frequency section for $\mathrm{D}$.

Greater error were obtained in the low frequency part between the test and prediction especially for less than $315 \mathrm{~Hz}$ mainly because wood belongs to the porous material, the sound transmission loss of low frequency is small and the error frequency of sound transmission loss is large. Besides, wood has a low resonance, which led to decreased transmission loss. Therefore, both the measurement error and the theoretical error lead to greater errors in the low frequency sound insulation and the nonlinear regression model. Meanwhile, the CLT and HCLT can effectively suppress the resonance phenomenon. It can clearly find that the sound insulation of HCLT is obviously higher than that of CLT by ignoring the material and the influence of test error. Therefore, it is very significance of the development of HCLT in the construction industry. 


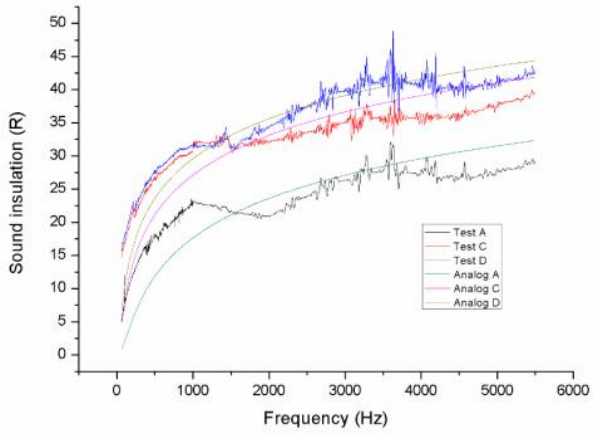

Fig. 8. Simulated sound insulation and measured value of HCLT

\section{Conclusions}

The wood sound insulation prediction was established by taking anatomical characteristics into account based on the derivation and verification of the transfer function. The simulated value was significantly related to the testing value at the level of 0.01 , which verified the feasibility of prediction. Theoretical value of sound insulation was predicted by regarding the substances in wood cell wall as equivalence to specific medium, which explained the effect of wood microscopic characteristic on the mechanism of sound insulation performance. The adjacent of earlywood and latewood was considered as sandwich structure in Masson pine and Southern pine for the calculation of sound insulation. The bonding interface was creatively introduced to improve the accuracy of sound insulation prediction. For LVL, it can not effectively improve the sound insulation by changing the type of adhesive. For CLT, it can not effectively change the amount of material sound insulation by changing the layer orientation of the CLT. The CLT and HCLT can effectively suppress the resonance phenomenon. It can clearly find that the sound insulation of HCLT is obviously higher than that of CLT by ignoring the material and the influence of test error. Therefore, it is very significance of the development of HCLT in the construction industry.

\section{Acknowledgement}

The authors thanks for the fundings from the National Key R\&D Program of China [grant numbers: 2017YFC0703501], the Natural Science Foundation of Jiangsu Province [grant numbers: Nos. BK20170926 and BK20150878], the Doctorate Fellowship Foundation of Nanjing Forestry University, the Postgraduate Research \&Practice Innovation Program of Jiangsu Province [grant numbers: KYCX18_0962] and the Priority Academic Program Development of Jiangsu Higher Education Institutions (PAPD). LERMAB is supported by the French National Research Agency through the Laboratory of Excellence ARBRE (ANR-12LABXARBRE-01).

\section{References}

1. G. Schickhofer, Cross Laminated Timber (CLT) in Europe-From Conception to Implementation, Presentation, Vancouver, Canada, 2010.

2. EN 16351, Timber Structures-Cross Laminated Timber-Requirements, European Committee for Standardization, Brussels, 2015.

3. R. Steiger, A. Gülzow, C. Czaderski, M. Howald, P. Niemz, Comparison of bending stiffness of crosslaminated solid timber derived by modal analysis of full panels and by bending tests of strip-shaped specimens, Eur. J. Wood Wood Prod, 70 (2012), 141-153.

4. S. Gagnon, C. Pirvu (Eds.), CLT Handbook: CrossLaminated Timber, FPInnovations, Vancouver, BC, Canada, 2011.

5. P. Fellmoser, H.J. Blaß, Influence of rolling shear modulus on strength and stiffness of structural bonded timber elements, in: Proceeding of CIB-W18 Meeting, Edinburgh, United Kingdom, (2004), 37-65.

6. M. Gong, D.Y. Tu, L. Li, Y.H. Chui, Planar shear properties of hardwood cross layer in hybrid cross laminated timber, in: Proceeding of the 5th International scientific conference on hardwood processing, Quebec City, Canada, Sept, (2015), 1517.

7. Z. Wang, H. Fu, M. Gong, Planar shear and bending properties of hybrid CLT fabricated with lumber and LVL, Construction and Building Materials, 151 (2017), 172-177.

8. L.L.Beranek. Noise Reduction, McGraw-Hill Book, (1960).

9. E Karacabeyli, B Douglas, CLT handbook: crosslaminated timber, FPInnovations and American Wood Council, USA Edition. (2013).

10. L Hu. CLT Buildings sound insulation, WCTE, (2012).

11. R.J. M.Craik. Sound transmission through building using statistical energy analysis, Gower Publishing Limited UK, (1996).

12. C. Zwikker, C. W. Kosten. Sound Absorbing Materials, Amsterdam: Elsevier, (1949).

13. K. Attenborough. Acoustical characteristics of porous materials, Phys, 82(1982), 179-227.

14. K. Attenborough. Acoustical characteristics of rigid fibrous absorbents and granular materials, J Acoust Soc Am, 73(1983), 785-799.

15. Biot A. Theory of propagation of elastic waves in a fluid-saturated porous solid-I:low-frequency range, J Acoust Soc Am, 28(1956), 168-178.

16. J. F. Allard. Propagation of sound in porous Media, London and New York: Elsevier Applied Science (1993).

17. D.K. Wilson, Relaxation-matched modeling of propagation through porous media including fractal pore structure, J Acoust Soc Am, 94(1993), 11361145. 
18. B. Fucheng, H. Li. Three dimensional flow resistance network of longitudinal gas permeation in coniferous wood, Forest science, 38(2002), 111-116.

19. J. Zehui, H. Qian, Z. Tianyi. Sound insulation simulation of softwood and wood composites, Wood. Sci. (In Processing)

20. H. Bryan, J. Stuart Bolton. A transfer-matrix approach for estimating the characteristic impedance and wave numbers of limp and rigid porous materials, J.Acoust. Soc. Am, 107(2000), 1131-1152.

21. Z. Zhenguo, Z. Xiuli, Z. Na. Study on sound insulation properties of materials by transfer matrix standing wave tube method, Materials Herald, 5(2010), 118-121.

22. W. Xinzhou, Nanoscale investigation of the interfacial properties and modification mechanism of wood-adhesive interphase, Nanjing Forestry University, (2016).

23. L. Xiaoning, C. Yucong, C. Ying. The Prediction of Elastic Modulus Along the Grain of Poplar Veneer, Journal of Nanjing Forestry University (Natural Science Edition), 3(2002), 9-13.

24. L. Xiaoning, W. Zhiqaing, D. Yicheng, G. Weijei. The Prediction of In-plane Shearing Modulus of Poplar Veneer, Journal of Nanjing Forestry University (Natural Science Edition), 1(2006), 93-94.

25. L. Xiaoning, H. Helang, D. Yicheng. The Prediction of Elastic Modulus in Tangential Direction of Poplar Veneer, Journal of Nanjing Forestry University (Natural Science Edition), 2(2003), 21-24.

26. C. Jianqiao. Introduction to mechanics of composite materials, Science Press Co.Ltd. CHINA Edition. (2006).

27. B.M. Suleiman, J. Larfeldt, J. Leckner, M. Gustavsson, Thermal conductivity and diffusivity of wood, Wood. Sci. Technol, 33(1999), 465-473. 